\title{
Functional capacity and risk of falls in the elderly with metabolic syndrome
}

\section{Capacidade funcional e risco de quedas em idosos com síndrome metabólica}

\section{Capacidad funcional y riesgo de caídas en ancianos con síndrome metabólico}

\author{
Ramon Repolês Soares ${ }^{1} \oplus$, Patrícia de Oliveira Salgado ${ }^{1} \oplus$, Kelvin Oliveira Rocha ${ }^{2 *} \oplus$, Luciana Moreira Lima ${ }^{1,3}(0)$ \\ ${ }^{1}$ Federal University of Viçosa, Postgraduate Program in Health Sciences, Department of Medicine and Nursing, MG, Brazil \\ 2 Federal University of Viçosa, Medicine Graduate student, Fapemig scientific fellowship, Department of Medicine and Nursing, MG, Brazil \\ ${ }^{3}$ Federal University of Viçosa, Postgraduate Program in Physical Education, Department of Physical Education, MG, Brazil
}

\begin{abstract}
Introduction: Metabolic syndrome (MetS) is the most common metabolic abnormality in the population that predisposes to cardiovascular events and may be related to poor physical fitness and low functional capacity in the elderly. The objective of this study was to evaluate the interference of metabolic changes in functional capacity and risk of falls in the elderly. Methods: A cross-sectional study was carried out with 126 elderly subjects, 58 presented MetS and 68 without MetS, according to the criteria of the International Diabetes Federation. Katz Index, Tinetti Index, Timed Up and Go test and Berg Scale were applied to evaluate the functional capacity. Falls Efficacy Scale-International scale (FES-I-Brazil) was used to evaluate the fear of falling. For statistical analysis, the Mann-Whitney, Chi-square and Spearman correlation tests were used. Results: There was an association between the MetS and non-MetS groups in relation to the risk strata of the TUG index [ $p=0.02 ; \mathrm{OR}=0.38 ; 95 \% \mathrm{Cl}(0.16-0.91)]$. Between these two groups, there was a significant difference in the mean of the following markers: Berg scale ( $p=0.03)$; TUG $(p=0.03)$; FES-I-Brazil $(p=0.02)$. The Kats and IPAQ index did not show any significant association. Conclusions: Elderly patients with MetS presented higher risk and fear of falls when compared to patients without MetS. However, there was no variation in walking ability or balance.
\end{abstract}

Keywords: Metabolic Syndrome; Aging; Functionality and Falls.

\section{Resumo}

Introdução: A síndrome metabólica (SM) é a anormalidade metabólica mais comum na população que predispõe a eventos cardiovasculares e pode estar relacionada à baixa aptidão física e baixa capacidade funcional em idosos. O objetivo deste estudo foi avaliar a interferência das alterações metabólicas na capacidade funcional e no risco de quedas em idosos. Métodos: Trata-se de um estudo transversal realizado com 126 idosos, sendo 58 com síndrome metabólica e 68 sem síndrome metabólica, segundo os critérios da International Diabetes Federation. Os índices de Katz, Tinetti, Timed Up e Go e Berg Scale foram aplicados para avaliar a capacidade funcional. A Escala de Eficácia das Quedas-Escala Internacional (FES-I-Brasil) foi utilizada para avaliar o medo de cair. Para análise estatística, foram utilizados os testes de correlação de Mann-Whitney, Qui-quadrado e Spearman. Resultados: Houve associação dos grupos MetS e non-MetS em relação com os estratos de risco do índice TUG $[p=0,02 ; \mathrm{OR}=0,38 ; \mathrm{IC} 95 \%(0,16-0,91)]$. Entre esses dois grupos, houve diferença significativa na média dos seguintes marcadores: escala de Berg $(p=0,03)$; TUG $(p=0,03)$; FES-I-Brazil $(p=0,02)$. O índice de Kats e IPAQ não apresentaram associação significativa. Conclusões: Os idosos com SM apresentaram maior risco e medo de quedas quando comparados aos pacientes sem SM. No entanto, não houve variação na capacidade de caminhar ou no equilíbrio.

Palavras-chave: Síndrome Metabólica; Envelhecimento; Funcionalidade e Quedas.

Como citar: Soares RR, Salgado PO, Rocha KO, Lima LM. Functional capacity and risk of falls in the elderly with metabolic syndrome. Rev Bras Med Fam Comunidade. 2020;15(42):2228. https://doi.org/10.5712/rbmfc15(42)2228
Autor correspondente:

Kelvin Oliveira Rocha.

E-mail: kelvin.rocha@gmail.com

Fonte de financiamento:

declaram não haver.

Parecer CEP:

Committee for Ethics in Research of the Federal University of Viçosa (CAAE 81072717.3.0000.5153). Procedência e revisão por pares: revisado por pares.

Recebido em: 07/10/2019.

Aprovado em: 06/04/2020. 


\section{Resumen}

Introducción: El síndrome metabólico (MetS) es la anormalidad metabólica más común en la población que predispone a eventos cardiovasculares y puede estar relacionado con un mal estado físico y una baja capacidad funcional en los ancianos. El objetivo de este estudio fue evaluar la interferencia de los cambios metabólicos en la capacidad funcional y el riesgo de caídas en los ancianos. Método: Se realizó un estudio transversal con 126 sujetos de edad avanzada, 58 presentaron MetS y 68 sin MetS, según los criterios de la Federación Internacional de Diabetes. Se aplicaron los índices Katz, Tinetti, Timed Up and Go y Berg Scale para evaluar la capacidad funcional. La Escala de Eficacia de las Caídas - Escala internacional (FES-I-Brasil) se utilizó para evaluar el miedo a las caídas. Para el análisis estadístico, se utilizaron las pruebas de correlación de Mann-Whitney, Chi-cuadrado y Spearman. Resultados: Hubo una asociación entre los grupos MetS y no MetS en relación con los estratos de riesgo del índice TUG $[p=0.02$; OR=0,38; IC 95\% (0.16-0.91)]. Entre estos dos grupos, hubo una diferencia significativa en la media de los siguientes marcadores: escala de Berg ( $p=0.03)$; TUG ( $p=0.03)$; FES-I-Brasil $(p=0.02)$. El índice de Kats e IPAQ no mostró ninguna asociación significativa. Conclusiones: Los pacientes de edad avanzada con síndrome metabólico presentaron mayor riesgo y miedo a las caídas en comparación con los pacientes sin síndrome metabólico. Sin embargo, no hubo variación en la capacidad para caminar o el equilibrio.

Palabras clave: Síndrome Metabólico; Envejecimiento; Funcionalidad y Caídas.

\section{INTRODUCTION}

Metabolic syndrome (MetS) represents a common abnormality in the population, affecting an expressive number of Brazilians, being the main responsible for the emergence of cardiovascular complications. Its pathogenesis is multifactorial, and the risk factors of abdominal obesity, dyslipidemia, hyperglycemia and hypertension associated with genetic mechanisms predispose the onset of cardiovascular diseases (CVD) and type 2 Diabetes mellitus (DM2). ${ }^{1}$

Individuals with MetS present important changes in physical fitness with decreased muscle strength and flexibility. Thus, these factors affect mobility, restricting daily functional activities and worsening the quality of life of this population. ${ }^{2}$ With the increase in life expectancy associated with the increasing prevalence of MetS in this population, high expenditures of government agencies in public health are needed. ${ }^{3}$

The biological changes during aging favor the evolution of MetS, which is closely related to the advanced age group. ${ }^{4}$ At the same time, the aging process is directly associated with a high prevalence of disability favoring the condition of dependence to perform daily activities, which can generate reduction in physical performance and motor skills. These changes in functional capacity predispose to the risk of falls, increase dependence and the appearance of fear in relation to new falls, causing a restriction of their routine activities, with a decrease in their functional mobility and consequent social isolation. ${ }^{5}$

Due to these issues, it is theorized that the presence of MetS in the elderly population is a factor that, due to its own social and pathophysiological characteristics, potentiates the deterioration of functional capacity, promoting greater risk and fear of falls. Based on this theoretical framework, this study aims to evaluate the hypothesis that elderly with MetS have a higher risk of falls than elderly without MetS in Viçosa/MG.

Thus, the study is justified by its practical and social applications. It proves important for proposing the verification of a potential risk factor for the local elderly population, besides contributing significantly to the scientific community. Moreover, there are few reports in the literature on the subject, besides characterizing a pioneer study in the region of Viçosa/MG, being essential to incite new research and open new questions, especially for primary care. 


\section{METHODS}

\section{Sample}

The population in study consists of elderly people from the region of Viçosa/MG (Brazil), who define people over 60 years of age. It is estimated that in this region there are 80 thousand inhabitants, where $10 \%$ consists in the elderly population, leading a population of approximately 8 thousand elderly people. A priori, the authors estimated a minimum sample of 117 patients, with a $95 \%$ confidence interval and $9 \%$ margin of error.

The sampling was carried out for convenience, performing it by inviting voluntary participation to the elderly who are monitored in the Third Age Municipal Program of Viçosa/MG. At the end of the study, the sample consisted in 126 participants, who were stratified into their participant groups according to the presence or absence of metabolic syndrome. In post-hoc analysis, a minimum sample was shown in 38 individuals from each group considering the FES-I-BRAZIL variable, which presented the highest coefficient of variation $(27.9 \%)$.

Elderly people with cognitive deficits, wheelchair users, bedridden, unable to perform the specific tasks of the questionnaires, and who did not sign the free and informed consent term were excluded.

\section{Ethics statement}

The study protocol was approved by the Committee for Ethics in Research of the Federal University of Viçosa (CAAE 81072717.3.0000.5153). All subjects signed legal consent forms. Information on demographic characteristics, lifestyle habits and perceived stress level was also assessed. All the individual and nonidentifiable data of the participants that support the results of this article are available from the moment of publication, indefinitely, for any person and purpose. ${ }^{6}$

\section{Data Collection}

Data were collected, between December 2018 and February 2019, by researchers who were previously trained and divided in a specific way for each questionnaire or test. Each evaluation instrument were applied by two researchers, who had previous training and practiced the application of the tests hours before starting the first day of collection.

All patients who chose to participate in the study voluntarily contributed to the requested physical activities. No patient participated in the planning, design and conduct of the study. Municipal senior program managers and employees contributed by publishing about the importance and possible benefits of the project to the local community. As a form of retribution, the authors of the present study provided the main results and conclusions about the data collected for the primary care units in Viçosa/MG and for the municipal elderly program in Viçosa/MG, in order to optimize care and care for the elderly in the local community. 


\section{Measures}

Initially, a semi-structured instrument was applied to investigate the following variables: gender, age, marital status, drug use, previous pathologies, blood pressure and waist circumference. Subsequently, the elderly were divided into two groups: MetS carriers and non-carriers. To determine the presence of MetS, the elderly were classified using the diagnostic criteria proposed by International Diabetes Federation (IDF). ${ }^{7}$ The volunteers with MetS presented abdominal circumference above $80 \mathrm{~cm}$ for women and $90 \mathrm{~cm}$ for men, associated with two of the following factors: systemic arterial hypertension $(\mathrm{SAH})$ or blood pressure $\geq 130 \times 85 \mathrm{mmHg}$; DM2 or glycemia $\geq 100 \mathrm{mg} / \mathrm{dL}$; high triglycerides ( $\geq 150 \mathrm{mg} / \mathrm{dL})$ and low HDL $(<40 \mathrm{mg} / \mathrm{dL}$ men and $<50 \mathrm{mg} / \mathrm{dL}$ women). Volunteers with DM2 and SAH, associated with waist circumference above the reference used, were automatically classified as having MetS. All patients were instructed to perform blood tests to assess lipid and glucose levels. Blood tests performed in the six months prior to data collection were used, without the need for a new examination.

To evaluate blood pressure, an aneroid sphygmomanometer was used, with an adult standard Velcro cuff from the Premium ${ }^{\circledR}$ brand, manufactured in July 2016 (Wenzhou Kangju Medical Instruments Co. Ltd.), duly calibrated. The volunteers were instructed on the need of having an empty bladder and not having used alcohol, tobacco or performed physical activity. The assessment was performed once after the volunteer maintained the sitting position, for five minutes.

In the evaluation of the abdominal circumference, the umbilical scar was used as reference and the measurement was made at the end of the respiratory expiratory movement, with the volunteer in the orthostatic position. To measure the waist circumference, we used fiberglass metric tapes graduated in millimeters with 1.5 meters of the Worker brand. ${ }^{8}$

\section{International Physical Activity Questionnaire (IPAQ)}

To assess the level of physical activity we used the International Physical Activity Questionnaire (IPAQ) proposed by the World Health Organization, validated in the literature by Pardini et al. ${ }^{9}$. The long version allows the analysis of physical activity in different domains by classifying the elderly in insufficient or sufficiently active. The IPAQ allows estimating the weekly time spent in physical activities of light, moderate and vigorous intensity. There are 27 questions regarding physical activities performed in a normal week, with light, moderate and vigorous intensity, divided into four categories of physical activity: work, transportation, domestic activities and leisure.

\section{Timed Up and Go (TUG) test}

TUG test is a validated test to evaluate the functional capacity of the elderly. The test consists of getting up from a chair from the sitting position with the back resting on the backrest, without the help of the arms, walking at a distance of three meters, turning around a cone and returning, turning and sitting again on the chair. To begin the test the volunteer received the instruction "go" and from there the time was timed from the voice command until the moment they again supported the back in the chair backrest. The test was performed once for familiarization and a second time for taking time. The evaluation was made through direct observation and timed in seconds. The volunteers were classified according to the time of execution: below 10 seconds - low risk of falls, 10 - 19 seconds - average risk of falls, and 20 seconds and more - high risk of falls. ${ }^{10}$ 


\section{Katz Index and Tinetti Scale}

The Katz Index evaluates the independence standard for performing daily life activities and the Tinetti Scale is used to evaluate balance and gait. The Katz Index is a functional evaluation instrument that allows assigning different degrees of functional independence to the elderly according to a final score. The elderly will be classified from $A$ to $G$, where $A$ and $B$ are classified as functional; $C, D$ and $E$ as intermediate functionality; $F$ and $G$ as less functional. ${ }^{11}$ The Tinetti Scale uses sixteen items that evaluate balance and gait generating a total score that determines fall risks. The score ranges from 0 to 28 , the higher the score the lower the risk of falls. The classification in relation to the scores is: $0-19=$ high risk of falls, $19-24=$ moderate risk of falls, and $25-28=$ low risk of falls. ${ }^{12}$

\section{Berg Scale}

To analyze the risk of falls, the Berg scale validated and adapted to the Brazilian culture was used. ${ }^{13}$ The Berg scale is used to evaluate elderly and patients with balance deficit, regardless of age, being an evaluation with simple materials (ruler, measuring tape, bench and stopwatch) that lasts approximately 15 minutes. The score ranges from 0 to 56 points: 1 - $36=$ high risk of falls, $37-44=$ safe locomotion with recommendation of device to aid walking, and $45-56=$ no risk of falls, safe locomotion. ${ }^{13}$

\section{Falls Efficacy Scale-International (FES-I-Brazil)}

The validated and culturally adapted Falls Efficacy Scale-International scale was applied to assess the fear of falling (FES-I-Brazil). ${ }^{14}$ This scale presents questions about the concern with the possibility of falling in relation to 16 activities, with respective scores of one to four, being 1 point for no concern about the decrease in relation to one of the activities, 2 points for a little worried, 3 points for very worried and 4 for extremely worried. The total score can range from 16 (no concern) to 64 (extreme worry). The classification of the elderly in relation to the questionnaire will be according to the total score: 16 points without concern; up to 32 mild concern; up to 48 moderate concern and up to 64 extreme concern.

\section{Statistical analysis}

The minimum size of the sample was defined using the coefficient of variation obtained for FESI-Brazil $(27.9 \%)$ in this study, considering ten percent of variation around the average, with a minimum number of thirty-five individuals each group. It was possible to verify statistical differences with a $5 \%$ level of significance. ${ }^{15}$

The data obtained in this research were tabulated in the program Statistical Package for the Social Sciences (SPSS), version 20.0. Initially, we analyzed the quantitative variables (Tinetti, Berg, Fes-I-Brazil e TUG). For the normality analysis, we adopted the Kolmogorov-Smirnov test and when the data were nonparametric, we applied the Mann-Whitney test. Qualitative variables were analyzed using Chi-square test and Fisher exact test, when appropriate. The Spearman test was used to verify the correlation between the variables Age; FES-I-Brazil; TUG; Berg and Tinetti. In all analysis, a 95\% confidence interval and significance level of $p \leq 0.05$ was considered. The sample power for the tests performed was above $80 \%$ for medium effect size and type I error probability at $5 \%$. 


\section{RESULTS}

The sample comprised 126 elderly people who regularly perform the activities proposed by the municipal program for the elderly, 58 of which (46\%) were classified as having MetS. The mean age in the MetS group was similar to the non-MetS group ( $69 \pm 6$ vs $69 \pm 7$, respectively). There was a higher prevalence of females in both the MetS group and the non-MetS group and the majority aged 60-69 years (Table 1).

In general, in both groups, the participants were independent when evaluated by the Katz Index, Tinetti test and Berg Scale, which evaluated mainly activities of daily living and balance. According to the Katz Index, in the MetS group, $98.3 \%(n=57)$ of the participants were independent and only $1.7 \%(n=1)$, partially dependent. In the group without MetS, all participants $(n=68)$ were independent. The Tinetti test revealed that more than $90 \%$ of participants had a low risk of falling. The low risk of falls was similar in the groups with and without MetS (94.8\% vs $97.1 \%$, respectively). Through the IPAQ, $62.1 \%$ of the elderly patients with MetS are insufficiently active, while only $45.6 \%$ of the elderly people without MetS have the same condition, suggesting a better level of physical activity in the elderly without MetS (Table 2).

Table 1. Distribution of gender and age strata in the MetS and non-MetS groups.

\begin{tabular}{lcccc}
\multicolumn{1}{c}{ Variable } & MetS $(\mathrm{n}=58)$ & Non-MetS $(\mathrm{n}=68)$ & $\mathrm{OR}^{\dagger}\left(\mathrm{IC}^{\ddagger} 95 \%\right)$ & $\mathrm{p}$ \\
\hline $\begin{array}{l}\text { Age } \\
\text { Gender }\end{array}$ & $69,0 \pm 6,3$ & $69,3 \pm 7,3$ & & $0,56^{\mathrm{M}}$ \\
$\quad$ Female & $52(89,7 \%)$ & $56(82,4 \%)$ & 1 & $0,24^{\mathrm{q}}$ \\
$\quad$ Male & $6(10,3 \%)$ & $12(17,6 \%)$ & $1,86(0,65-5,31)$ & \\
& & & & \\
Age Group & & & & \\
$\quad 60-69$ years & $31(53,4 \%)$ & $38(55,9 \%)$ & $1,10(0,55-2,23)$ & $0,78^{\mathrm{q}}$ \\
70-79 years & $23(39,7 \%)$ & $23(33,8 \%)$ & $0,78(0,38-1,61)$ & $0,49^{\mathrm{q}}$ \\
80-89 years & $4(6,9 \%)$ & $7(10,3 \%)$ & $1,55(0,43-5,58)$ & $0,50^{q}$ \\
\hline
\end{tabular}

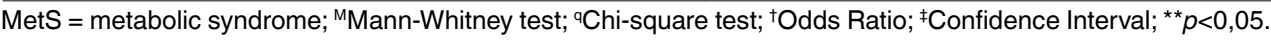

Table 2. Distribution and association of indices and their respective strata as a function of the MetS and non-MetS groups.

\begin{tabular}{|c|c|c|c|c|}
\hline Variable & MetS $(n=58)$ & Non-MetS $(n=68)$ & $\mathrm{OR}^{\dagger}\left(\mathrm{IC}^{\ddagger} 95 \%\right)$ & $p$ \\
\hline \multicolumn{5}{|l|}{ Kats Index } \\
\hline Low fall risk & $1(1,7 \%)$ & $0(0 \%)$ & 1 & $0,46^{f}$ \\
\hline Moderate fall risk & $57(98,3 \%)$ & $68(100 \%)$ & $2,38(0,21-26,9)$ & \\
\hline \multicolumn{5}{|l|}{ Tinetti Test } \\
\hline Low fall risk & $55(94,8 \%)$ & $66(97,1 \%)$ & 1 & $0,66^{\dagger}$ \\
\hline Moderate fall risk & $3(5,2 \%)$ & $2(2,9 \%)$ & $0,62(0,14-2,92)$ & \\
\hline \multicolumn{5}{|l|}{ IPAQ } \\
\hline Sufficiently active & $22(37,9 \%)$ & $37(54,4 \%)$ & 1 & $0,06^{q}$ \\
\hline Insufficiently active & $36(62,1 \%)$ & $31(45,6 \%)$ & $0,52(0,26-1,06)$ & \\
\hline \multicolumn{5}{|l|}{ Berg Scale } \\
\hline With aid device & $1(1,7 \%)$ & $1(1,5 \%)$ & 1 & $1,00^{f}$ \\
\hline Without aid device & $57(98,3 \%)$ & $67(98,5 \%)$ & $1,17(0,16-8,59)$ & \\
\hline \multicolumn{5}{|l|}{ Timed Up and Go } \\
\hline$<10$ s & $40(69,0 \%)$ & $58(85,3 \%)$ & 1 & $0,02^{q^{* x}}$ \\
\hline $10-19 s$ & $18(31,0 \%)$ & $10(14,7 \%)$ & $0,40(0,17-0,93)$ & \\
\hline \multicolumn{5}{|l|}{ FES-I-Brazil } \\
\hline No concern & $2(3,4 \%)$ & $3(4,4 \%)$ & 1 & $0,33^{\dagger}$ \\
\hline Slight concern & $44(75,9 \%)$ & $58(85,3 \%)$ & $0,98(0,21-4,62)$ & \\
\hline Moderate concern & $11(19 \%)$ & $7(10,3 \%)$ & $0,50(0,08-2,86)$ & \\
\hline Extreme concern & $1(1,7 \%)$ & $0(0 \%)$ & $0,38(0,02-6,35)$ & \\
\hline
\end{tabular}

MetS = metabolic syndrome; IPAQ = International Questionnaire of Physical Activity; FES-I-Brazil = Falls Efficacy Scale International validated in Brazil; ${ }^{\mathrm{a}} \mathrm{Chi}$-square test; ${ }^{\mathrm{f}}$ Fisher exact test; ${ }^{\dagger}$ Odds Ratio presented by the Haldane-Anscombe correction; ${ }^{\ddagger}$ Confidence Interval; ${ }^{* *} \mathrm{p}<0,05$. 
Analyzing the risk of falling and the fear of falling, it can be observed through the Berg Scale that there is no risk in $98.3 \%(n=57)$ of the MetS elderly, characterizing a safe locomotion without the help of an aid device. The same result was found in the participants of the group without MetS $(98.5 \% ; n=67)$. However, the TUG and FES-I-Brazil tests presented worse results in the MetS group compared to the nonMetS group. The TUG test revealed that the MetS group had a higher prevalence of mean risk of falling compared to the non-MetS ( $31 \%$ vs $14.7 \%$, respectively). The FES-I-Brazil test showed that $20 \%$ of the elderly in the MetS group presented moderate to extreme fear of falling, but only $10 \%$ of the elderly in the non-MetS group showed the same concern. The results of TUG and FES-I suggest that the MetS group presents twice the worry and risk of fall compared to non-MetS (Table 2).

When stratified by age group, a higher percentage of under-active elderly in both groups at ages 80-89 years, with similar values, is observed through IPAQ. However, a high number of insufficiently active patients in the MetS group compared to the non-MetS group (64.5\% vs 36.8\%, respectively) were observed in the sexagenarians.

In Table 3, it is possible to observe that when comparing the scores of the Tinetti, Berg Scale, FESI-Brazil and TUG tests, significant differences were found between the two groups in the evaluation of the balance and the Gait, fear of fall and functional capacity.

In the MetS group, there was a statistically moderate negative correlation between Age and Berg ( $r=-$ 411, $p=0.01)$, a negative statistically weak correlation for FES-I-Brazil and Berg $(r=-365, p=0.05)$ and Berg and TUG $(r=-0.353, p=0.007)$. There was also a positive correlation between the Berg and Tinetti variables $(r=0,395, p=0.002)$ and a positive statistically moderate correlation between Age and TUG $(r=0.418, p=0.001)$.

For the group without MetS, there was a statistically weak negative correlation between age and Berg $(-0.363, p=0.002)$, Berg and FES-I-Brazil $(-0.258, p=0.03)$; a statistically moderate negative correlation for Berg and TUG ( $r=-0.422, p=0.00)$; a statistically weak positive correlation between age and TUG $(r=0.346$, $p=0.004)$; FES-I-Brazil and TUG $(r=290, p=0.016)$ and Berg and Tinetti $(r=0.304, p=0.01)$.

\section{DISCUSSION}

When separating the sample studied in two strata, MetS and non-MetS, it was possible to observe an association of MetS with two variables: risk of falling and fear of falling. On the other hand, there was no significant association between physical activity and physical dependence, level of physical activity and gait performance and balance. In the comparison of functional capacity and risk of falls in elderly with and without MetS, we verified that the results of the Tinetti Index, Katz Index and the Ipaq were without significant differences between the groups. The TUG, Berg scale and FES-I-Brazil presented relevant differences with lower levels of functional capacity and high risk of falls for the elderly with MetS.

Table 3. Mean and standard deviation of respective tests scores in the MetS and non-MetS groups.

\begin{tabular}{lccc}
\multicolumn{1}{c}{ Variable } & MetS $(\mathrm{n}=58)$ & Non-MetS $(\mathrm{n}=68)$ & $\mathrm{P}$ \\
\hline Tinetti Test & $27,1 \pm 1,3$ & $27,2 \pm 1,2$ & $0,57^{\mathrm{M}}$ \\
Berg Scale & $53,3 \pm 2,7$ & $54,0 \pm 2,5$ & $0,03^{\mathrm{M} * *}$ \\
Timed Up and Go (seconds) & $9,5 \pm 2,1$ & $8,8 \pm 1,7$ & $0,03^{\mathrm{M} * *}$ \\
FES-I-Brazil & $26,9 \pm 8,0$ & $23,8 \pm 5,6$ & $0,02^{\mathrm{M} * *}$ \\
\hline
\end{tabular}

MetS = metabolic syndrome; FES-I-Brazil = Falls Efficacy Scale International validated in Brazil; ${ }^{* * M M a n n-W h i t n e y ~ t e s t ; ~}{ }^{* *} p<0,05$. 
The presence of a higher risk of falls in elderly patients with MetS corroborates some aspects already described in the literature. Barr points out that in elderly patients, the presence of peripheral neuropathy and radiculopathies can be evident even under conditions of good glycemic control, especially in sedentary and obesity conditions. ${ }^{16}$ The presence of peripheral neuropathy, especially in the lower limbs, presents a potential relation with proprioception impairment, influencing significantly the risk of falls. ${ }^{16,17}$ In addition, other risk factors that are commonly related to MetS in the elderly are presented as aggravating factors for the risk of falls, such as: sedentary behavior, physical conditions and presence of morbidities. ${ }^{18}$

It is already well established that the risk of falling in the elderly population is related to several risk factors, many of which are a natural consequence of the aging process itself. Physiologically, the musculoskeletal function presents significant atrophy as the age advances. The loss of muscle strength in the lower limbs shows progressively over the years and may present a decrease in strength of up to $40 \%$ at 70 years when compared to 20 years of age. When considering the association with MetS, the risk of falls is enhanced by the association of neuropathy and muscle weakness, with a sensory dysfunction added to motor impairment. ${ }^{16}$

Also reported in the literature is the association between dysfunction in glucose metabolism and vestibular dysfunction in the elderly, generating gait and balance disturbance and predisposing to the risk of falls. Bittar et al. ${ }^{19}$ point out that a significant portion of the population presenting dizziness has complications such as DM2 and MetS, and that there is a significant correlation with vestibular problems and dysfunction of glucose metabolism. Dizziness and vertigo in the elderly population are usually associated with vestibular dysfunction or adverse drug effects, directly affecting patient gait and balance. Since it affects gait and balance, there is a significant association between dizziness and an increased risk of falls in this population. Although this association exists, the sample studied in this study, despite presenting a high risk of falls, was not associated with gait imbalance or balance in the presence of MetS. This finding, explored by the Tinetti scale, leads us to believe that MetS offers a high risk of falls without significantly affecting vestibular function. ${ }^{17,18,19}$

In the present study, the fear of falling, evaluated by the FES-I-Brazil scale, presented a slight correlation with the risk of falls, evaluated by the Berg score and the TUG test. This finding corroborates other studies, which justify the presence of fear of falls in patients due to the risk of recurrent falls. ${ }^{20}$ Thiamwong and Suwanno ${ }^{20}$ define fear of falling as a lack of self-confidence regarding achievements of daily activities, resulting in harm to the patient, such as social isolation, sedentary lifestyle and decreased quality of life. As a result, there is greater deterioration of physical capacities and formation of a vicious cycle, recursively generating greater risk of falls. ${ }^{21}$

The presence of fear of falling in patients with MetS was significantly higher, corroborating the hypothesis that the concomitance of MetS may increase the fear of falling in the elderly population. It has already been described in the literature that changes in glucose metabolism significantly increase the frequency and intensity of fear of falling. Hewston and Deshpande ${ }^{22}$ show that frequency and intensity of fear of falling is strongly related to the presence of DM2 and emphasize that this issue goes beyond the physical domain or influence of peripheral neuropathies, also involving psychosocial issues. In addition, Jindal et al. ${ }^{23}$ point out that there is a significantly positive association between fear of falling and loss of organic function, use of multiple medications and depression.

In this reasoning, it is clear the importance of primary care to prevent falls in this population. The development of preventive measures requires multidisciplinary approaches, involving professionals from different health areas, where close contact and self-care with the elderly can be performed with greater efficiency and effectiveness, especially in patients with DM2 and MetS. 


\section{Limitations}

The limitations of this study are presented by the characteristics intrinsic to its proposal. As it was a transversal work, prospective questions could not be evaluated. In addition, due to its objectivity, this work was limited in evaluating the abovementioned indexes, without evaluating the sociodemographic characteristics or biochemical values of the population. Finally, other factors that may limit functional capacity and increase the risk of falls in the elderly were not considered, such as: orthopedic, neurological and cardiac impairments, drugs that can interfere with the reproduction of the elderly and factors that facilitate the risk of falls.

The future steps, based on the evidence found in this sample, will be to evaluate other issues that can work together with MetS compromising quality of life, such as: sociodemographic aspects, dietary pattern, knowledge and attitude about the disease and biochemical aspects.

\section{CONCLUSIONS}

Elderly patients and patients with MetS presented higher risk and fear of falls when compared to patients without MetS, however, there was no variation in gait ability and balance. Preventive methods in primary care are the best ways to improve the quality of life of this population, especially in the presence of comorbidities such as MetS. This study presents evidence that corroborates the premise that elderly people with MetS have a higher risk of falls and may be a target population for preventive measures.

\section{Highlights}

The study demonstrates the importance of assessing and intervening in functional capacity and without risk of falls in elderly people with metabolic syndrome. Functional capacity may suffer a negative influence in the presence of MetS as a comorbidity, increasing the risk and fear of falls in the elderly. Preventive methods in primary care are the best ways to improve the quality of life of this population, especially in the presence of comorbidities such as MetS. This study presents evidence that corroborates the premise that elderly people with MetS have a higher risk of falls and may be a target population for preventive measures.

\section{Key points}

The study reinforces that there is a relationship between MetS with functional incapacity and risk of falls in the elderly. Elderly with MetS are at a higher risk of falls than older people without MetS.

\section{ACKNOWLEDGEMENTS}

The authors thank the Municipal Program of the Third Age (PMTI) for the support to the research, mainly to the elderly of the program that made themselves available to participate in the research.

\section{Conflicts of interest}

The authors declare that they have no conflict of interest in this study.

\section{Academic linkage}

This article is part of the master's dissertation of Ramon Repolês Soares, student at the Postgraduate Program in Health Sciences, Federal University of Viçosa - UFV. 


\section{REFERENCES}

1. Lam DW, Leroith D. Metabolic syndrome. In: Feingold KR, Anawalt B, Boyce A, et al., eds. Endotext. South Dartmouth, MA: MDText.com, Inc.; 2000 .

2. Peterson MD, AI Snih S, Stoddard J, Shekar A, Hurvitz EA. Obesity misclassification and the metabolic syndrome in adults with functional mobility impairments: nutrition examination survey 2003-2006. Prev Med. 2014 Mar;60:71-6.

3. Luedy A, Barreto DL, Costa-Ribeiro Júnior H. Impact of metabolic-syndrome risk factors on the absenteeism of health workers from a Brazilian University Hospital. Health. 2018 Jun;10(6):853-77.

4. Dominguez LJ, Barbagallo M. The biology of the metabolic syndrome and aging. Curr Opin Clin Nutr Metab Care. 2016 Jan;19(1):5-11.

5. Cvecka J, Tirpakova V, Sedliak M, Kern H, Mayr W, Hamar D. Physical activity in elderly. Eur J Transl Myol. 2015 Aug;25(4):249-52.

6. Soares RR, Rocha KO, Salgado PO, Lima LM. Functional capacity and risk of falls in the elderly with metabolic syndrome - database. Zenodo. 2020 Mar 30; [Epub ahead of print]. DOI: https://doi.org/10.5281/zenodo.3733531

7. International Diabetes Federation (IDF). IDF consensus worldwide definition of the metabolic syndrome [Internet]. Brussels: IDF; 2006; [access in $2017 \mathrm{Jul}$ 26]. Available from: https://www.idf.org/e-library/consensus-statements/60-idfconsensus-worldwide-definitionof-the-metabolic-syndrome.html

8. International Society for the Advancement of Kinanthropometry (ISAK). International standards for anthropometric assessment. Lower Hutt, New Zealand: ISAK; 2011.

9. Pardini R, Matsudo SMM, Matsudo VKR, Araújo T, Andrade E, Braggion GF, et al. Validation of international physical activity questionnaire (IPAQ): pilot study in Brazilian young adults. Med Sci Sports Exerc. 1997;29(6):5-9.

10. Podsiadlo D, Richardson S. The timed "Up \& Go": a test of basic functional mobility for frail elderly persons. J Am Geriatr Soc. 1991 Feb;39(2):142-8.

11. Katz S, Ford AB, Moskowitz RW, Jackson BA, Jaffe MW. Studies of illness in the aged. The index of ADL: a standardized measure of biological and psychosocial function. JAMA. 1963 Sep;185(12):914-9.

12. Tinetti ME. Performance oriented assessment of mobility problems in elderly patients. J Am Geriatr Soc. 1986 Feb;34(2):119-26.

13. Berg KO, Wood-Dauphinee SL, Williams JI, Maki B. Measuring balance in the elderly: validation of an instrument. Can J Public Health. 1992 Jul/Aug;83(Suppl 2):S7-S11.

14. Yardley L, Beyer N, Hauer K, Kempen G, Piot-Ziegler C, Todd C. Development and initial validation of the falls Efficacy Scale-International (FES-I). Age Ageing. $2005 \mathrm{Nov} ; 34(6): 614-9$.

15. Hulley SB, Cummings SR. Estimating sample size and power. In:Designing clinical research.Philadelphia:Lippincott Williams and Wilkins; 1988. p. 148.

16. Barr KP. Electrodiagnosis in the patient with metabolic syndrome: adding value to patient care. Phys Med Rehabil Clin N Am. 2018 Nov;29(4):735-49.

17. Lord SR, Delbaere K, Sturnieks DL. Aging. Handb Clin Neurol. 2018;159:157-71.

18. Cuevas-Trisan R. Balance problems and fall risks in the elderly. Clin Geriatr Med. 2019 May;35(2):173-83.

19. Bittar RSM, Santos MDA, Mezzalira R. Glucose metabolism disorders and vestibular manifestations: evaluation through computerized dynamic posturography. Braz J Otorhinolaryngol. 2016 Jul/Aug;82(4):372-6.

20. Thiamwong L, Suwanno J. Fear of falling and related factors in a community-based study of people 60 years and older in Thailand. Int $\mathrm{J}$ Gerontol. 2017;11(2):80-4.

21. Jeon MY, Gu MO, Yim JE. Comparison of walking, muscle strength, balance, and fear of falling between repeated fall group, one-time fall group, and nonfall group of the elderly receiving home care service. Asian Nurs Res (Korean Soc Nurs Sci). 2017 Dec;11(4):290-6.

22. Hewston P, Deshpande N. Fear of falling and balance confidence in older adults with type 2 diabetes mellitus: a scoping review. Can J Diabetes. 2018 Dec;42(6):664-70.

23. Jindal HA, Duggal M, Jamir L, Sharma D, Kankaria A, Rohilla L, et al. Mental health and environmental factors associated with falls in the elderly in North India: a naturalistic community study. Asian J Psychiatr. 2019 Jan;39:17-21. 